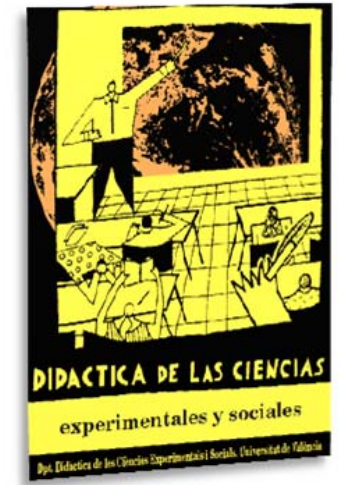

\title{
La represión franquista en los manuales escolares: el problemático tratamiento de un tema histórico conflictivo
}

\author{
Francoist repression in school textbooks: the \\ problematic treatment of a controversial \\ historical topic
}

DOI: $10.7203 / D C E S .37 .12528$

\author{
Carlos Fuertes Muñoz \\ Universitat de València, carlos.fuertes@uv.es \\ Mélanie Ibáñez Domingo \\ Universitat de València, melanie.ibanez@uv.es
}

\begin{abstract}
RESUMEN: Este artículo analiza de forma panorámica el tratamiento de la represión franquista en los manuales escolares españoles de educación secundaria y bachillerato de los últimos veinticinco años. Se parte de la siguiente premisa: el tratamiento educativo de un pasado conflictivo como el del franquismo, y en particular, de la represión, es fundamental en la construcción de la cultura democrática entre las nuevas generaciones. En este sentido, el artículo focaliza su atención en las carencias interpretativas y metodológicas apreciables en los libros de texto publicados bajo la vigencia de las leyes educativas LOGSE, LOE y LOMCE.
\end{abstract}

Palabras Clave: franquismo, represión franquista, didáctica de la Historia, manuales escolares, educación secundaria.

ABSTRACT: This article analyzes in a panoramic way the treatment of the Francoist repression in the Spanish school textbooks of secondary and high school education of the last twenty-five years. It is based on the following premise: the educational treatment of a conflictive and "hot" past like that of Franco's regime and, especially, Francoist repression, is basic in the construction of democratic culture among the new generations. In this sense, the article focuses on the interpretative and methodological deficiencies that can be seen in the textbooks published under the LOGSE, LOE and LOMCE educational laws.

KEYWORDS: Francoism, Francoist repression, didactics of History, school textbooks, secondary education.

Fecha de recepción: mayo de 2018 Fecha de aceptación: julio de 2018

El autor forma parte de los proyectos de investigación EDU2015-65621-C3-1-R “Competencias sociales para una ciudadanía democrática: análisis, desarrollo y evaluación” (Subproyecto: “La educación formal en los procesos de construcción de identidades y su relación con las competencias sociales”) y PGC2018-094491-B-C32 “Las representaciones sociales de los contenidos escolares en el desarrollo de las competencias docentes”.

La autora forma parte del grupo de investigación de excelencia GEHTID (Grup d’Estudis Històrics sobre les Transicions i la Democràcia); programa Prometeo de la Generalitat Valenciana (GVPROMETEO2016-108). 


\section{LA DICTADURA FRANQUISTA: DE LA SOCIEDAD A LAS AULAS}

Pese a los importantes consensos de la historiografía académica, la dictadura franquista sigue constituyendo bien avanzado el siglo XXI, un tema histórico “conflictivo” o "candente” (López Facal y Santidrían, 2011) en la sociedad española, en la cual conviven visiones enfrentadas sobre la misma (Bernecker y Sören, 2009). ¿Por qué? Podríamos aducir múltiples razones y responsables. Una dictadura de casi cuatro décadas, con la consiguiente penetración de determinados discursos a través de la educación formal e informal (Valls, 1984 y 2009). Una “modélica” transición que no se basa en la denuncia categórica de la dictadura y, por tanto, la convierte en un periodo reciente no cerrado o cerrado en falso. Un amplio sector de la clase política, que ha tolerado durante décadas la pervivencia de símbolos, discursos e injusticias de origen franquista. Buena parte de las élites culturales y mediáticas, mediante la difusión de una narrativa equidistante que tiende a equiparar moralmente a "vencedores” y "vencidos" en la Guerra Civil; también, en casos aislados pero de notable influencia, recuperando una narrativa franquista que cuestiona las numerosas investigaciones y aportaciones de la historiografía académica (Aguilar, 1996 y 2006; Rodrigo, 2004; Santamaría, 2013). Sin embargo, lejos de perspectivas elitistas y sin que ello suponga menoscabar su incidencia o responsabilidad, muchos de estos discursos y políticas se explican en última instancia por su arraigo social. La imagen benévola, banalizada y acrítica del franquismo entre buena parte de los apoyos de la derecha actual; o la difusión social de una memoria traumática y más o menos equidistante de la Guerra Civil y la dictadura entre amplios y heterogéneos sectores sociales son, en este sentido, elementos clave. Ambos ayudan a entender la aún escasa demanda social de memoria democrática, pese a los avances registrados en este sentido en los últimos quince años: la emergencia pública del llamado "Movimiento por la Recuperación de la Memoria Histórica” y el impulso de las políticas públicas de memoria democrática a nivel estatal, autonómico y municipal (Aguilar, 2006; Saz, 2007: 29-32; Fuertes, 2017: 109-148).

Todos estos problemas generales tienen su plasmación específica en las aulas. Investigaciones sobre el alumnado de instituto y universidad apuntan a un panorama ciertamente complejo y matizado, en el que muchos manifiestan interés por el periodo y opiniones de rechazo. No obstante, también abundan las actitudes ambivalentes e insuficientemente críticas con la dictadura franquista, asociadas al desconocimiento de aspectos clave de su historia, particularmente de aquellos relacionados con el antifranquismo y la represión. Alrededor de un $45 \%$ de los estudiantes del IES Fray Luis de León de Salamanca de $4^{\circ}$ de ESO y Bachillerato encuestados en 2006-2007 no consideraba que fuese necesario reparar a las víctimas de la represión franquista e impulsar una Ley de Memoria Histórica -aprobada en 2007-, siendo inferior al 50\% quienes eran conscientes del distinto trato dispensado históricamente a las víctimas de la violencia política desatada a partir de 1936 (Molpeceres, 2011: 27-28). Entre una muestra de estudiantes de Magisterio encuestados en 2013-2014, un 58\% desconocía qué fue el Tribunal de Orden Público, mientras que tan solo un 18\% era consciente de que las ejecuciones políticas se mantuvieron hasta los últimos compases del franquismo (Hernández, 2014: 66).

Junto al contexto sociopolítico y familiar, el propio alumnado apunta a un factor clave de estas actitudes: el insuficiente y superficial tratamiento de la dictadura franquista en numerosas aulas de $4^{\circ}$ de ESO y -aunque en menor medida- $2^{\circ}$ de Bachillerato (Hernández, 2014: 66-67). Dicha realidad debe asociarse a la disparidad social en torno al tema, que lleva a muchos profesores a evitar o pasar de puntillas por el período por temor a generar discusiones (López Facal y Santidrían, 2011). Pero también al tratamiento que el franquismo recibe en los manuales escolares, recurso abrumadoramente hegemónico en la enseñanza de la historia en niveles preuniversitarios; $y$, por ello, de incuestionable influencia potencial en la configuración del imaginario histórico del alumnado y del profesorado, que tiende a utilizarlo como eje articulador de sus clases (Burguera, 2006). 
Así las cosas, las investigaciones realizadas muestran ciertamente las innegables mejoras tanto a nivel metodológico como conceptual a partir de los años noventa, con el consiguiente abandono de las narrativas de abierta exaltación de "el régimen" que caracterizaron a los manuales publicados durante el franquismo. Y la paralela difusion de un discurso global crítico, enfatizando negativamente su carácter dictatorial, la represión y la ausencia de libertades. Pese a ello, el tratamiento de la dictadura franquista en los manuales de los últimos veinticinco años sigue caracterizándose por una insuficiente perspectiva crítica y actualización respecto a la historiografía académica. También, en estrecha relación, por un tratamiento superficial, descriptivo y no problematizado de aspectos clave para la formación de la juventud, dada su proximidad temporal y su significado en y para la actualidad, contribuyendo de ese modo a la reproducción o no cuestionamiento de discursos legitimadores del franquismo difundidos en canales de socialización extra-escolares como los medios de comunicación o la familia (Valls, 2009: 97, 108-109, 151-160; Boyd, 2006: 98; Ibáñez, 2016: 62-64; Fuertes, 2018).

Entre los aspectos clave tratados de forma inadecuada se encuentra la represión practicada por la dictadura (Valls, 2009: 68; Díez, 2012; Hernández, 2014: 69-70). Un elemento clave para la construcción de una ciudadanía y de una cultura democrática, dada su centralidad en el debate público sobre la llamada "memoria histórica” y el enorme potencial crítico y emotivo que alberga su tratamiento en las aulas. Sobre esta específica temática nos detendremos en las siguientes páginas. A partir de la revisión de las investigaciones históricas y didácticas precedentes y del análisis de una selección de manuales de las editoriales de mayor difusión -Anaya, Santillana, Vicens Vives, SM y ECIR-, trazaremos una panorámica general sobre el tratamiento de la represión franquista en los libros de texto de $4^{\circ}$ de ESO y $2^{\circ}$ de Bachillerato durante las etapas de la LOGSE, la LOE y la actual LOMCE.

\section{LA REPRESIÓN FRANQUISTA, DE LA HISTORIOGRAFÍA ACADÉMICA A LA HISTORIOGRAFÍA ESCOLAR}

La conflictividad -cuando no invisibilidad- que suscita el franquismo en el espacio público o mediático no se ve reflejada en el ámbito de la historiografía académica. Existe un amplio consenso entre los historiadores especializados a la hora de afirmar que el archiconocido último parte no significó el final de la Guerra Civil. El fin de las estrategias militares es considerado una "formalidad" (Carrillo, 2007: 75); y la dictadura franquista, una larga "paz incivil" (Casanova, 2002: 5) o una "paz retórica” (Rodrigo, 2008: 162). La durísima y brutal represión que había comenzado con la Guerra Civil y el afán de venganza que habían mostrado los sublevados se ejecutaría con plenitud tras la ocupación total del territorio.

La represión tuvo un carácter central y estructural en la dictadura franquista. Todos los especialistas parten en sus análisis de considerar la violencia como un elemento básico a la hora de analizar su naturaleza, además de una pieza clave para entender su mantenimiento. Francisco Moreno (1999: 227) define la violencia, no como algo episódico, sino como un componente fundamental del franquismo. Julio Aróstegui (2012: 21) se refiere al franquismo como un "sistema represivo”. Julián Casanova (2002: 8) alude a la represión como la "médula espinal” de la dictadura de Franco. O Javier Rodrigo (2008: 163) apuesta por caracterizar la violencia como "estructural y preventiva” - y no coyuntural y reactiva- para ayudar a comprender sus "continuidades y readaptaciones". Señala que "el franquismo echó las bases de su larga duración en la enorme inversión en violencia realizada en la guerra y la posguerra, para después ir administrando sus rentas” (en la misma línea, Preston, 2011: 615). Por su parte, Michael Richards (1999: 25) plantea que la represión no fue algo inevitable: el terror "fue programado, pensado e intencionado" como "medida de profilaxis social y política” para lograr la destrucción total del enemigo político.

¿Se han traslado estas conclusiones y consensos a los manuales? A partir de los libros para los nuevos cursos de $4^{\circ}$ de ESO y $2^{\circ}$ de Bachillerato introducidos por la LOGSE, se aprecia un 
tratamiento más analítico y detallado de la gran represión inicial; con menos silencios que en los manuales de $8^{\circ}$ de EGB y $3^{\circ}$ de BUP y con un mayor énfasis en su centralidad como base para el asentamiento y larga duración de la dictadura (Valls, 2009: 93, Marina, 2015: 53). Sin embargo, el tema de la represión franquista, aunque generalizado y raramente mitigado, negado o excusado de forma explícita, se ha caracterizado a menudo -de forma mucho más evidente en los manuales de $4^{\circ}$ aunque también en los de $2^{\circ}$ - por una insuficiente perspectiva crítica, profundización y actualización científica (Valls, 2007: 68; Díez, 2012: 160; Hernández, 2014: 69-70; Ibáñez, 2016: 62-64). Problemas más difíciles de detectar que en épocas anteriores pero localizables a través de una lectura entre líneas atenta a la estructuración, la extensión, los matices, los énfasis y los silencios.

Desde luego, no se trata de caer en sospechas excesivas y simplificadoras, como algunos autores que llegan a considerar que la no calificación de "genocidio" a la represión franquista supondría una voluntad consciente de minimización de la misma por parte de los autores de los manuales (Sánchez-Lafuente, 2008). Alejada de análisis tan poco matizados, Boyd (2006: 97) escribía que los "textos conservadores" del período LOGSE se diferencian de los "textos progresistas", entre otras cosas, en que "no se detienen en la represión franquista". En un análisis sobre libros de $4^{\circ}$ publicados entre 2008 y 2011 -bajo la LOE- se destaca cómo, a diferencia de Vicens Vives, los de Anaya o SM “mencionan” la represión “como un componente más de la posguerra”. Mientras, en Edelvives “ni siquiera se aborda” (Marina, 2015: 53-54). Igualmente, un amplio estudio de un equipo de la Universidad de León sobre 21 libros de $4^{\circ}$ de $\mathrm{ESO}$ y $2^{\circ}$ de Bachillerato del período LOE señala la mayor superficialidad y acriticismo con la que es tratada en aquellos manuales, mayoritarios, que son calificados como "conservadores" y "políticamente correctos”. Así, se lamenta cómo la conceptualización más rigurosa, actualizada, detallada y explicativa de la represión franquista, la que enfatiza su carácter sistemático y planificado, únicamente estaría presente en un tercio de los manuales analizados, de forma destacada en los de Vicens Vives y Akal (Díez, 2012: 69-171).

La superficialidad y la falta de detalle apreciables en los manuales LOGSE y LOE, son en buena medida consecuencia del escaso espacio - en términos de páginas- que se le presta a la represión. En comparación, por ejemplo, con el dedicado a la economía, la política exterior; o, en el conjunto de la secuencia Guerra Civil-Franquismo, a las batallas militares (Díez, 2012: 148, 154, 173). Esto se aprecia incluso en manuales como el de Vicens Vives para $2^{\circ}$ de Bachillerato publicado en 2003 por, entre otros, Julio Aróstegui, gran especialista en la represión franquista. Pese a que puede considerarse un libro ampliamente actualizado, riguroso y crítico en su conceptualización del fenómeno represivo, este aparece restringido a un único epígrafe de dos páginas en el que son tratadas de forma somera "exilio, represión y resistencia” (Aróstegui et al., 2003: 324-325). Una cuestión probablemente propiciada, o cuando menos no mitigada, por un currículum educativo enciclopédico y que apenas ha dado relevancia al estudio de la represión. Resulta sumamente llamativo en este sentido que incluso en el muy detallado diseño curricular de 1992 para la asignatura de "Historia de España" de $2^{\circ}$ de Bachillerato, no haya ni una sola referencia explícita a la "represión franquista”. Más en un plan de estudios que sí incluía, de forma enormemente novedosa respecto al anterior de 1975, cuestiones como las "realizaciones” de la II República, los conceptos de "sublevación militar” y "Guerra Civil”, "la oposición democrática a la dictadura” o “el exilio” (Valls, 2009: 23-24, 34).

Respecto a los manuales de la LOMCE, un primer análisis de los de $2^{\circ}$ de Bachillerato publicados por las editoriales de mayor difusión -SM, Santillana, Anaya y Vicens Vives-, nos permite detectar la continuidad, a grandes rasgos, de la superficialidad y del resto de problemas detectados en los manuales de los períodos LOGSE y LOE. Todos inciden en la importancia de la represión en la caracterización y larga duración del franquismo, si bien no todos lo hacen con la misma contundencia y profundidad, especialmente en lo relativo a su continuidad en el tiempo y diversidad de formas. Se constata que Vicens Vives sigue siendo, en esta ocasión con algo más de detalle que en 2003 -2 páginas para la represión de posguerra-, el manual más actualizado, crítico y 
riguroso. También el que impulsa una mayor participación y reflexión del alumnado, articulando el epígrafe "Investiga: La represión sobre los vencidos" en torno al análisis cruzado de diversas fuentes estadísticas, informes internos de las autoridades y declaraciones públicas legitimando la represión (Álvarez et al., 2016: 362-363).

Por el contrario, el libro de Anaya resulta en conjunto el menos actualizado, reflexivo y crítico tanto en lo que se refiere al tratamiento del franquismo en general, como en lo relativo específicamente a la represión. Muy ilustrativo es que -al igual que SM (Pereira y Mata, 2016: 278279)- no incluya la represión dentro del epígrafe inicial dedicado a "Las bases del régimen franquista” entre las que únicamente sitúa los “ingredientes ideológicos”, las "bases sociales” y las "leyes fundamentales del Estado". Asimismo, la frase con la que encabeza el apartado dedicado a "La represión política”, profundiza en la minimización de la represión franquista, predisponiendo al alumnado hacia su normalización. Se afirma sin matices que "Una guerra civil nunca termina el día en que se firma el último parte de la contienda". De forma ahistórica y enormemente simplista, se da a entender implícitamente que todas las guerras civiles van seguidas inevitablemente de una represión como la que desplegó el franquismo (García de Cortázar et al., 2016: 313-320)

\section{LA REPRESIÓN FRANQUISTA EN PERSPECTIVA COMPARADA}

Este último ejemplo remite a otra problemática: la ausencia en los manuales de referencias comparativas que permitirían al alumnado comprender con más claridad la enorme y extraordinaria magnitud de la represión franquista sobre la población civil en tiempos de paz, superior a la registrada en cualquier posguerra civil española anterior. Superior también a la practicada sobre el enemigo político interno a la comunidad nacional "imaginada" en las dictaduras nazi y fascista italiana. Estas, a diferencia del franquismo, acotaron la represión a los líderes del movimiento obrero y las izquierdas, tratando de integrar activamente a sus bases en el nuevo sistema (Saz, 1999: 12-18). Otra cuestión clave remite al establecimiento de comparaciones con la violencia practicada en la zona republicana durante la Guerra Civil. Desde el inicio, la violencia en retaguardia y/o contra civiles fue un elemento inherente al conflicto bélico. Sin embargo, como han demostrado las investigaciones históricas (Richards, 1999: 25, 31; Gil, 2012: 25; Cenarro, 1998: 25-26), el carácter de dicha violencia no fue el mismo en el territorio bajo control republicano y el ocupado por los sublevados. Las acciones violentas en la zona republicana fueron un fenómeno trágico, pero concentrado mayoritariamente en los primeros meses de la contienda. La represión franquista se desplegó a lo largo de todo el conflicto -y tras su finalización-. Por otro lado, la denominada "violencia revolucionaria" fue un fenómeno esencialmente descentralizado y producto de una actitud defensiva, no siendo planeada por las autoridades estatales como un ataque a los considerados enemigos de clase. Asimismo, el gobierno republicano se mostró públicamente siempre contrario al empleo del terror político. Su actitud se encontraba alejada de los planes internos, alocuciones y declaraciones de algunos de los principales líderes golpistas que apelaban al uso de la brutalidad y presumían de la necesidad de eliminar enemigos.

A este respecto, los libros de $2^{\circ}$ de Bachillerato, y particularmente aquellos que Boyd (2006: 97) califica como "progresistas", insisten más a menudo en la diferenciación de la violencia republicana destacando el carácter sistemático, planificado y estructural de la represión franquista (Valls, 2009: 98, 101-102; Lamikiz, 2011: 100-101). Sin embargo, la pervivencia social e intelectual de una narrativa equidistante sobre la Guerra Civil tendría una manifestación evidente en la realización en numerosos manuales tanto de $4^{\circ}$ como de $2^{\circ}$ de un reparto equitativo de la responsabilidad moral por las atrocidades de retaguardia, aunque este haya sido matizado. Estas son presentadas todavía en no pocos libros sugiriendo sutilmente que son intercambiables - "terror rojo" y "terror blanco"- y a grandes rasgos muy similares tanto en su naturaleza y objetivos como en las

\footnotetext{
${ }^{1}$ La cursiva es nuestra a lo largo de todo el artículo.
} 
víctimas producidas, no subrayándose suficientemente sus evidentes diferencias (Boyd, 2006: 9697; Valls, 2009: 91-93; Díez, 2012: 107, 135, 146, 171, 177). En la misma línea apunta el mencionado estudio de la Universidad de León: destaca como una clara mayoría de los 21 libros de $4^{\circ}$ y $2^{\circ}$ analizados -incluyendo editoriales de gran difusión como Santillana, ECIR, Anaya, Oxford o McGraw Hill- asumen total o parcialmente una postura equidistante. Minimizan abiertamente o, cuando menos, no analizan de manera sistemática y actualizada todas las diferencias entre la represión franquista y la violencia practicada durante la guerra en la zona controlada por el gobierno democrático (Díez, 2012: 135, 156, 160, 173, 179-182).

\section{LOS TIEMPOS DE LA REPRESIÓN}

Otra cuestión fundamental es la propia periodización de la represión. La historiografía académica ha insistido con frecuencia en su carácter permanente. Aunque varió su intensidad y formas, en gran medida como consecuencia de la eficacia de la gran "inversión" en terror realizada al inicio, jamás dejó de ser el elemento clave en la relación del Estado con la sociedad hasta los años setenta. En efecto, tras la represión sobre los partidarios y defensores de la República, la dictadura siguió persiguiendo de forma implacable, sistemática y perfectamente organizada, cualquier intento de contestación al “Nuevo Estado”. Jamás se planteó la integración de la disidencia (Rodrigo, 2008: 183). Si bien los procesos sumarísimos, las ejecuciones y las medidas más sonadas tuvieron lugar en la primera década, la represión no fue sólo un fenómeno de los primeros años de la dictadura. El franquismo actualizó sus métodos represivos a lo largo del tiempo, pasando por ejemplo del estado de guerra a los estados de excepción o de los consejos de guerra nunca completamente desaparecidos- a la creación del civil pero excepcional Tribunal de Orden Público en 1963, que hasta la propia transición condenó a penas de prisión a miles de españoles y españolas (Del Águila, 2001).

Una represión que no por menor cuantitativamente es menos relevante cualitativamente. Entre otras cuestiones porque ayudaría a que el alumnado entendiese con más claridad otro importante rasgo particular del franquismo en el marco de la historia contemporánea de España. Esto es: su continua y sistemática negación y persecución de las libertades y derechos individuales y colectivos más básicos, tales como el de expresión, reunión, asociación, huelga o manifestación. En este sentido, uno de los principales problemas detectados es la clara concentración de los manuales en la represión practicada en la inmediata posguerra. Es harto frecuente, especialmente en los de $4^{\circ}$ pero no únicamente, la imprecisión y la falta de énfasis en su continuación hasta los años setenta como elemento estructural de la dictadura (Valls, 2009; Díez, 2012: 156; Marina, 2015: 53). El peligro es evidente: el alumnado puede percibir implícitamente que efectivamente se trató de una cuestión coyuntural normalizada en un contexto de (pos)guerra civil.

A este respecto, el libro de ECIR para $2^{\circ}$ de Bachillerato LOGSE muestra una variante de este problema: la tendencia a presentar la represión limitada a los primeros años y como consecuencia de la inicial relevancia de Falange asociada a la influencia exterior nazi y fascista. La represión, excluida del epígrafe introductorio más general sobre "Los fundamentos del nuevo régimen”, es despachada con un breve párrafo en el apartado sobre "La etapa azul (1939-1945)"; incluido en un epígrafe sobre "El franquismo durante la Segunda Guerra Mundial”. Como contrapartida, este manual asocia la derrota del fascismo internacional al "progresivo relegamiento de los falangistas" y la creciente influencia "católica”. Entonces, impulsaría una "concesión incompleta de derechos a los ciudadanos" - refiriéndose al Fuero de los Españoles- y una "aproximación a los partidos conservadores europeos". El proceso culminaría con "el ascenso de los tecnócratas” a finales de los cincuenta, quienes promulgaron "leyes que regulaban la actuación del poder político" y "una gestión eficaz” promoviendo "un mayor desarrollo económico y social” (García et al., 2003: 361365). 
Si desplazamos la mirada hacia el tratamiento de la cronología de la represión en los manuales más recientes de $2^{\circ}$ de Bachillerato, los publicados en 2016, el panorama no muestra cambios de calado respecto a lo apreciado en manuales de las etapas LOGSE y LOE. En los cuatro libros que hemos analizado hay un claro desequilibrio entre el tratamiento de la represión de la inmediata posguerra -más detallado y con epígrafe u apartado propio- y el de la represión posterior contra el maquis, las organizaciones políticas y sindicales antifranquistas o los movimientos obrero, estudiantil y vecinal, entre otros. En este caso, se aborda de modo muy superficial, sin apartado propio y sin apenas fuentes documentales, estadísticas o testimoniales. Cabe incidir, particularmente, en la total invisibilidad de la represión sufrida en relación con las luchas y actitudes de estudiantes y profesores en los institutos del tardofranquismo (Martín, González y Ortiz, 2009; Sánchez, 2012), cuyo tratamiento permitiría una mayor conexión con el alumnado de Secundaria y Bachillerato.

Anaya aborda el conjunto de la dictadura en una única unidad didáctica, excluyendo la represión -como ya hemos señalado- del epígrafe inicial dedicado a "Las bases del régimen franquista". Únicamente aparece un apartado propio dedicado a "La represión política" dentro del epígrafe sobre "los años cuarenta”. No hay referencias a la represión durante "Los años cincuenta" y se limita, en los epígrafes sobre los sesenta-setenta, a varias pinceladas en forma de imágenes, cuadros y frases. Frases que, en varias ocasiones, asumen de forma acrítica el lenguaje sobre la represión difundido por la propia dictadura con ánimo de legitimarla presentándola como un efecto o reacción inevitable y normalizada ante los conflictos sociales. Por ejemplo, se afirma que la sustitución del falangista Sindicato Español Universitario (SEU) "por asambleas libres de alumnos” acabó "provocando continuas intervenciones de la policía” (García de Cortázar et al., 2016: 344),

En general en los manuales actuales se tiende a criticar el supuesto "aperturismo" del régimen en sus últimos años, describiéndolo como una forma de "maquillaje" para salvaguardar el sistema dictatorial y como una respuesta frente a las crecientes protestas sociales. Sin embargo, afirmaciones de ese tipo chocan con el tratamiento global de la unidad o epígrafe dedicado a los últimos veinte años, centrado en gran medida en los "logros" del "desarrollismo" y con un énfasis en el nuevo perfil "más técnico que ideológico" y "reformista” de la "nueva generación de políticos" franquistas (Álvarez et al., 2016: 404). Nuevos políticos de quienes se obvian los aspectos más oscuros, como cuando al trazar una breve biografía de Manuel Fraga se omite su rol central en la maquinaria propagandística y la represión de las protestas sociales durante los sesenta e incluso durante la transición (Fernández Ros et al., 2016: 345). Todo ello, contribuye en conjunto a dibujar implícitamente entre el profesorado y el alumnado la idea de un "segundo franquismo bueno o menos malo" vinculado a un proyecto "modernizador" y "aperturista” que habría culminado con la monarquía democrática; idea fuertemente arraigada en el imaginario social y mediático, aunque rigurosamente cuestionada por la historiografía académica (Aguilar y Humlebaek, 2002; Saz, 2008).

\section{LAS FORMAS DE LA REPRESIÓN Y EL TRATAMIENTO DIDÁCTICO DE LA MEMORIA}

La falta de atención al periodo posterior a la inmediata posguerra se aprecia también al analizar el tratamiento de las diversas formas que asumió la represión franquista. Los manuales, especialmente los de $2^{\circ}$, suelen atender a distintos modos de represión, aunque rara vez se analizan con detalle o se alude a su carácter complementario (Ibáñez, 2016: 62-66; Díez, 2012: 160). Se aprecia el predominio de una visión reduccionista de la represión, centrada en los fusilamientos practicados en la inmediata posguerra: "la mayoría de los libros de texto (...) se concentran en presentar la represión prácticamente como una suma de muertes, sin ver más allá”. Igualmente, suele subrayarse el mucho mayor número de víctimas mortales de la represión franquista en su conjunto, pero en muchas editoriales la cuantificación es escasa: "las cifras de la represión son 
tratadas como 'de puntillas”” e "incluso obviadas por su posible conflictividad” (Díez, 2012: 181182).

En ocasiones, los fusilamientos son descritos sin incidir en "quién, cómo, ni por qué se fusilaba”, siendo escasas las referencias a las cunetas, las fosas comunes, los “desaparecidos”, las ejecuciones extrajudiciales -“paseos”- (Díez, 2011: 230; Sánchez-Lafuente, 2008) o los asesinados mediante la aplicación de la "ley de fugas" en el contexto de la persecución de la guerrilla antifranquista y sus apoyos. Respecto al periodo posterior, si bien es frecuente la atención a las ejecuciones políticas más conocidas del tardofranquismo -como la del comunista Grimau (1963) o el anarquista Salvador Puig Antich (1974)- ninguno de los manuales LOMCE analizados atiende a los asesinatos extrajudiciales de obreros y estudiantes en manifestaciones y comisarías durante los años sesenta y setenta. Una práctica represiva fundamental para entender la naturaleza de la dictadura en su última etapa y que necesita ser subrayada con mayor fuerza para lograr generar entre el alumnado una comprensión inequívocamente crítica y atenta a los hechos.

Tampoco se atiende en los manuales a la continuidad en los años cincuenta, sesenta y setenta de otra modalidad clave de la represión franquista: la experiencia de la detención y la reclusión. En la posguerra, cuando cientos de miles de personas pasaron por las cárceles y centros habilitados franquistas (Moreno, 1999: 278-301; Gómez, 2009) sí es habitual la referencia a la existencia de presos políticos. Sin embargo, la cuantificación resulta a menudo confusa y poco actualizada (García et al., 2003: 362), obviándose o pasándose de puntillas por dimensiones clave como las numerosas muertes por enfermedad en el interior de las prisiones. Igualmente, se aprecia la parca atención a cuestiones como las torturas en los centros de detención (Díez, 2012: 157, 173, 179-180). Un excepcional ejemplo, muy poco presente, es un ejercicio propuesto en SM: "busca los centros de internamiento franquista que hubo en tu provincia” (Pereira y Mata, 2016: 283)-. Una referencia de cómo podemos conseguir un mayor interés y participación del alumnado mediante la atención al desarrollo de la represión en su entorno local, para lo cual también podríamos recurrir a los archivos locales y provinciales (Tribó, 2005). Respecto a los campos de concentración franquistas (Rodrigo, 2001), su tratamiento resulta insuficiente y mejorable en numerosos libros, dado su impacto social y su relevancia para una educación crítica. Ello contrasta llamativamente en el caso de $4^{\circ}$ de ESO con la detallada atención que los mismos libros prestan a los campos de concentración en Francia y Alemania durante la Segunda Guerra Mundial. Buscado o no, el efecto es que muchos alumnos pueden deducir "con esos silencios que aquí no pudo nadie ser tan cruel” (Sánchez-Lafuente, 2008: 199).

Igualmente, es escasa la atención en los libros de $4^{\circ}$ a la utilización de presos republicanos como mano de obra esclava o semi-esclava en trabajos forzados o "redención de penas" al servicio del Estado y las grandes empresas (Hernández, 2014: 72). Sobre esta cuestión clave que está siendo objeto de interés creciente por la historiografía académica (Climent, 2016), apreciamos una cierta mejoría en los manuales de $2^{\circ}$ más recientes. En Vicens Vives se destaca la creación en 1940 de los Batallones Disciplinarios de Soldados Trabajadores, "integrados por reclutas [republicanos] considerados peligrosos para incorporarse al ejército”, señalando que en 1942 había 46.678 hombres realizando, entre otras, "obras de reconstrucción de carreteras, puentes, líneas ferroviarias y obras hidráulicas” (Álvarez et al., 2016: 362). En Anaya, se mencionan distintos tipos de trabajos forzados, refiriéndose a los mismos como "crueles condenas" e incluyendo un testimonio retrospectivo de gran emotividad de un prisionero andaluz que los padeció. Este destaca el hambre, el durísimo trabajo, la solidaridad recibida por parte de vecinos e incluso de un alférez; pero también el rencor que aún siente por los represores en pleno siglo XXI (García de Cortázar et al., 2016: 320). Un buen ejemplo del enorme potencial didáctico de las fuentes orales y testimoniales para el estudio de la historia (Prades, 2016), debiendo lamentarse en este sentido su absoluta excepcionalidad en los manuales analizados. Y, en relación con ello, la total ausencia del recurso a las entrevistas a familiares o vecinos para indagar en la historia y la memoria de la violencia política franquista. De hecho, las dos únicas actividades de este tipo que incluyen los manuales LOMCE 
analizados se centran en la "vida cotidiana” y las “costumbres" durante la posguerra y el desarrollismo, buscando probablemente evitar temas que, como la represión, pudieran suscitar mayores debates y polémicas entre el alumnado.

En relación con estos trabajos forzados, es frecuente la referencia mediante fotografías al “Valle de los Caídos”. Sin embargo, en numerosas ocasiones no va acompañada de una explicación sobre su construcción por parte de trabajadores forzados ni sobre su funcionalidad política, en todo un ejercicio de uso acrítico de uno de los iconos propagandísticos más relevantes del franquismo. Además, dada su centralidad mediática y sociopolítica, es de esperar que el alumnado tenga referencias. Un pie de foto de un libro de ECIR lo describe como un "colosal monumento en recuerdo de los muertos del régimen" y se limita a afirmar de forma impersonal que "se construyó entre 1940 y 1959” (García et al., 2003: 375). En claro contraste, el libro de Santillana para $2^{\circ}$ LOMCE dedica su sección final sobre "La historia en tu vida" a "El Valle de los Caídos: del enaltecimiento a la reconciliación”, describiendo los objetivos originales y la participación de presos en la construcción del mausoleo. Asimismo, reflexiona sobre los planteamientos respecto a este edificio previstos en la Ley de Memoria Histórica e incita al alumnado a "investigar": sobre "la polémica que ha suscitado y los argumentos de los diferentes partidos políticos”; y sobre "si todavía se siguen haciendo actos de homenaje en el monumento y quienes los realizan”, incluyéndose una fotografía reciente de partidarios del franquismo (Fernández Ros et al., 2016: 333).

Con esta actividad y con otras anteriores, Santillana nos presenta un buen ejemplo de cómo podemos suscitar un mayor interés entre el alumnado mediante la atención a los debates y controversias actuales sobre la memoria histórica. Una estrategia didáctica que, pese a excepciones crecientes, sigue sin ser suficientemente utilizada por los manuales escolares. No abundan las referencias a las reivindicaciones y políticas públicas relacionadas con la eliminación de símbolos franquistas del espacio público, la exhumación de fosas comunes o la reparación de las víctimas de la dictadura. Tampoco hay apenas referencias a los procesos de amnistía de represores y represaliados durante la transición; ni a los enormes problemas relacionados con las fuentes históricas necesarias para una comprensión rigurosa de la represión franquista. Problemas tales como la destrucción de documentación en los estertores de la dictadura y la transición o las graves deficiencias de su conservación, catalogación y acceso (Valls, 2007: 67-69; 2009: 94, 155; Lamikiz, 2011: 105-107; Díez, 2012: 107, 111, 131, 168, 173).

\section{LA HISTORIA SOCIOCULTURAL DE LA REPRESIÓN FRANQUISTA EN LOS MANUALES ESCOLARES}

La concentración de los manuales en los fusilamientos y en el universo carcelario va asociada a la escasez de un enfoque sociocultural en el tratamiento del franquismo, y de la represión en particular, en unos manuales que siguen primando la macro-historia político-institucional (Fuertes, 2018). Este enfoque sociocultural tiene un notable potencial para conectar con el alumnado y se ha revelado de gran interés en la investigación histórica sobre la represión. Entre otras aportaciones, ha enriquecido notablemente nuestra comprensión sobre su profunda y vasta repercusión en la sociedad española, muy superior a la que afectó estrictamente a presos y fusilados. En cuanto a su traslación a los manuales escolares, rara vez se subraya el carácter de “clase” de la represión franquista -que se cebó con los sindicatos y las clases trabajadoras-; ni la continuidad de la represión económica hasta el final de la dictadura, en forma, por ejemplo, de las numerosas y cuantiosas multas e inhabilitaciones impuestas por el Tribunal de Orden Público. En muchos casos encontramos visiones superficiales, confusas y poco actualizadas de fenómenos masivos como las depuraciones laborales o la incautación de bienes de las personas y organizaciones vinculadas a la defensa de la República. En relación con ello, apenas se menciona el derivado "proceso de enriquecimiento y generación de nuevas fortunas que asentaron la oligarquía del régimen” (Díez, 2012: 157, 173, 179-180). O el tratamiento de la Ley de Responsabilidades Políticas de 1939 
(Álvaro, 2006; Ibáñez, 2017), clave en la represión económica, es a menudo inadecuado e incurre en graves errores factuales, como afirmar que "envió a cárceles y campos de concentración”, sirviendo para el "exterminio" y la "ejecución” de los enemigos políticos (García de Cortázar et al., 2016: 307, 321).

En lo que se refiere a la represión cultural, moral e intelectual que afectó al conjunto de la ciudadanía a través del sistema educativo, la censura, el control de la vida cotidiana, el ocio, la estética o las relaciones afectivas si bien esta suele ser ciertamente mencionada en la mayor parte de los manuales, quedan invisibilidades elementos clave de la misma (Hernández, 2014: 72). Por ejemplo, la represión sobre homosexuales y lesbianas, tendría un evidente potencial motivador para un alumnado joven que fácilmente podría empatizar con estas temáticas, dado el contexto actual de aceptación mayoritaria de la diversidad sexual. Asimismo, no se enfatiza suficientemente el carácter represivo de los procesos de nacionalización española (con la excepción de Álvarez et al., 2016: 360 y 363) y recristianización impulsados por la dictadura con el apoyo de diversos sectores sociales.

Igualmente, son excepcionales los manuales que subrayan con claridad la colaboración alentada por el Estado (Gómez y Marco, 2011: 181-195)- de una parte de la sociedad la humillación cotidiana y la delación de los vencidos (Díez, 2012: 158-159, 183). También es escaso el énfasis el papel de actores como el Ejército -piénsese en los simulacros de juicio que representaban los Consejos de Guerra o en las declaraciones públicas de Franco o Queipo de Llano- (Marco, 2012); o la Iglesia -tanto a través de la legitimación propagandística como de la colaboración cotidiana en la censura y en la persecución, con denuncias u omitiendo avales- (Hernández, 2014: 72; Castillejo, 2015: 17-19).

Si ponemos el foco en las actitudes, percepciones y experiencias de las víctimas de la represión, el balance es similar. Apenas son retratados los heterogéneos perfiles de los represaliados; ni abordado el drama de la vida cotidiana en las prisiones y centros de detención (Gómez, 2009), la estigmatización, la “presión ambiental” y las dificultades socioeconómicas fuera de ellos (Vinyes, 2004: 24; Moreno, 1999: 277-278; Rodrigo, 2008: 16). Muchos manuales no profundizan en los llamados “efectos no contables” de la represión (Mir, 1999: 138; Calzado, 2015: 208) en forma de miedo, trauma o humillación, que afectaron no solo al individuo sino a su entorno (Gómez, 2009: 199, 208). Elementos todos ellos que ayudarían al alumnado a comprender la profundidad de la herencia a largo plazo de la represión franquista. De forma general, suele subrayarse cómo la represión contribuyó a asentar un consentimiento pasivo mayoritario basado en el miedo, pero no se insiste en el paralelo malestar que generó y en su creciente ineficacia en la última etapa de la dictadura, cuando se multiplicaron las movilizaciones contra la represión y las actitudes de rechazo (Fuertes y Gómez, 2011).

Respecto a quienes trataron de huir de la represión franquista, cabe lamentar que el exilio sigue siendo tratado con escasas excepciones (Pereira y Mata, 2016: 283) con un enfoque centrado en la minoría de exiliados pertenecientes a las élites intelectuales, científicas y políticas. Se ignoran las particulares $-\mathrm{y}$ a menudo más duras- experiencias de las clases populares, las mujeres, los ancianos y los niños que constituían la gran mayoría de quienes huyeron del país (Alted, 2005). En buena parte de los libros de $4^{\circ}$ analizados por Hernández (2014: 72), se presta una muy escasa atención a "la entidad y magnitud del exilio", así como a la vivencia de la Segunda Guerra Mundial por parte de los exiliados, tanto en la resistencia antifascista como en los campos de concentración nazis. Respecto a los exiliados retornados -bien detenidos por los nazis en Francia, bien atraídos por las falsas promesas franquistas- no suele enfatizarse lo suficiente la represión que sufrirían, al igual que tampoco suele mencionarse el caso de los "topos", de la temprana emigración política a las ciudades; o del resto de formas que asumió durante décadas el llamado “exilio interior” (García et al., 2003: 362; Fernández Ros et al., 2016: 322).

Por último, cabe destacar que la escasez del enfoque sociocultural deviene ausencia si hablamos de perspectiva de género. Es absoluta la falta de atención de los manuales LOGSE, LOE 
y LOMCE a las importantes particularidades de género en la represión franquista (Sánchez, 2009; Egido, 2011. Sin embargo, en los manuales, se ha destacado la tendencia a reducir la represión franquista sobre las mujeres a la imposición de los modelos de feminidad conservadores y la consecuente pérdida de los derechos adquiridos durante la Segunda República. Aun así, no siempre subrayando con claridad el enorme retroceso educativo, laboral o jurídico que sufrieron las mujeres, o el hecho de que la represión moral y sexual se cebó de forma destacada con ellas (Molinero, 1999; Di Febo, 2006).

Se obvian las diversas causas y formas de represión sufridas específicamente por las mujeres vencidas. Por ejemplo, las acusaciones propias por el mero hecho de ser esposas, novias, hermanas o madres de republicanos; los castigos específicos o las particulares experiencias carcelarias y judiciales sufridas por las vencidas (Aguado, 2009; Moreno, 2013). De modo particular, cabe resaltar la invisibilidad en los manuales de las torturas específicas sufridas por las mujeres (Joly, 2008), tales como las violaciones y otras formas de abuso sexual, la ingesta de aceite de ricino, el rapado de pelo o el ocultamiento del paradero de sus familiares varones (Díez, 2012: 161-162, 181; Ibáñez, 2016: 62-66). La ausencia de enfoque de género en el tratamiento de la represión tiene otras consecuencias como la invisibilidad de fenómenos clave: la cuestión de los “niños robados” en las cárceles de mujeres (Vinyes, 2002) o las formas de rechazo y resistencia a la represión protagonizadas fundamentalmente por las llamadas "mujeres de preso" a lo largo del conjunto de la dictadura (Abad, 2007). Tampoco se adopta una perspectiva de género al analizar la participación y el apoyo a la represión, la cual permitiría apreciar la particular implicación en la represión de monjas y activistas católicas, funcionarias de prisiones, militantes de la Sección Femenina o viudas de “caídos” y otras familiares de víctimas de la violencia revolucionaria (Langarita, 2016).

\section{Conclusiones}

El análisis realizado, centrado en la selección y enfoque de los contenidos conceptuales, muestra un panorama complejo y diverso, pero en el que es frecuente encontrar en los manuales de las últimas décadas visiones de la represión franquista insuficientemente críticas, poco actualizadas y superficiales. Un tratamiento que, en conjunto, da poca visibilidad a elementos clave para la construcción de una memoria democrática y una ciudadanía comprometida con los derechos humanos. Tampoco coadyuva la priorización, en la mayor parte de los manuales analizados, de un modelo de enseñanza-aprendizaje escasamente problematizador. Un modelo que, salvo excepciones, potencia más la memorización pasiva que la reflexión, la motivación y la participación del alumnado mediante la atención a los debates públicos sobre la "memoria histórica" o la indagación en la (micro)historia de la represión a nivel familiar o local. Todas ellas son estrategias básicas si un manual de Historia pretende conectar con los discentes y generar un aprendizaje significativo (Rüsen, 1997; Prats, 2012: 12).

En conjunto, frente a estos problemas se hace necesario que el profesorado adopte una actitud reflexiva y activa, seleccionando y utilizando críticamente los manuales escolares. En este sentido, que se prioricen aquellos libros, epígrafes o actividades que fomenten un estudio más problematizador, reflexivo y actualizado del tema, en la línea de algunos de los ejemplos esperanzadores analizados en este artículo. Al tiempo, deben planificarse otras propuestas sirviéndose de guías didácticas especializadas (Fuertes y Verdugo, 2017) y de otros muchos recursos existentes para el estudio de la dictadura. Véase, por ejemplo, el uso de las fuentes orales, el patrimonio local o el análisis de documentación escrita y gráfica. Por último, pero no menos importante, debemos interpretar con flexibilidad el currículum a fin de dedicar más tiempo a temas históricos relevantes que, como la represión franquista, son fundamentales para la construcción de la cultura democrática de las nuevas generaciones, finalidad elemental del sistema educativo. 


\section{Referencias}

Abad, I. (2007). Las mujeres de los presos políticos. Represión, solidaridad y movilización en los extramuros de las cárceles franquistas, 1936-1977. Zaragoza: Universidad de Zaragoza.

Aguado, A. (2009). Repressió franquista i identitats femenines. En P. Pagès (Ed.), La repressió franquista al País Valencià. Primera Trobada d'Investigadors de la Comissió de la Veritat (pp. 133-158). València: Tres i Quatre.

Aguilar, P. (1996). Memoria y olvido de la Guerra Civil española. Madrid: Alianza Editorial.

Aguilar, P. (2006). La evocación de la guerra y del franquismo en la política, la cultura y la sociedad españolas. En S. Juliá (Dir.), Memoria de la guerra y del franquismo (pp. 279-317). Madrid: Taurus.

Aguilar, P. y Humlebaek, C. (2002). Collective Memory and National Identity in the Spanish Democracy. The Legacies of Francoism and the Civil War. History and Memory, 14, 121164. DOI:10.1353/ham.2002.0001.

Álvarez, L., García, M., Gatell, C., Gibaja, J.C. y Risques, M. (2016). Historia de España. $2^{\circ}$ Bachillerato. Madrid: Vicens Vives.

Álvaro, M. (2006). «Por ministerio de la Ley y voluntad del Caudillo». La Jurisdicción Especial de Responsabilidades Políticas (1939-1945). Madrid: CEPC.

Aróstegui, J., García, M., Gatell, C., Palafox, J., Risques, M. (2003). Historia. Bachillerato. Segundo Curso. Barcelona: Vicens Vives.

Aróstegui, J. (2012). Coerción, violencia, exclusión. La dictadura de Franco como sistema represivo. En J. Aróstegui (Coord.), Franco, la represión como sistema (pp. 19-59). Barcelona: Flor del Viento.

Bernecker, W.L. y Sören, B. (2009). Memorias divididas. Guerra Civil y franquismo en la sociedad y la política españolas (1936-2008). Madrid: Editorial Abada.

Boyd, C. (2006). De la memoria oficial a la memoria histórica: la Guerra Civil y la Dictadura en los textos escolares de 1939 al presente. En S. Juliá (Dir.), Memoria de la guerra y del franquismo (pp. 79-99). Madrid: Taurus.

Burguera, J. (2006). Usos i abusos del llibre de text. Perspectiva escolar, 302, 75-79.

Calzado, A. (2015). La Valldigna. Un món en conflicte (1931-1979). València: La Xara.

Carrillo, M. (2007). La legislació repressiva de la dictadura franquista en el període 1939-1959. En P. Pagés (Dir.), Franquisme i repressió. La repressió franquista als Països Catalans (pp. 75101). València: PUV.

Casanova, J. (2002). Una dictadura de cuarenta años. En J. Casanova (Coord.), Morir, matar, sobrevivir. La violencia en la dictadura de Franco (pp. 2-50). Barcelona: Biblioteca de Bolsillo.

Castillejo, E. (2015). La memoria eclesial de la guerra civil española y su transmisión en la historiografía escolar. En G. Gómez y R. Pallol (Eds.), Actas del Congreso Posguerras. 75 aniversario del fin de la guerra civil española. Madrid: Fundación Pablo Iglesias.

Cenarro, A. (1998). Muerte y subordinación en la España franquista: el imperio de la violencia como base del «Nuevo Estado». Historia Social, 30, 5-22.

Climent, J.M. (2016). El treball esclau durant el franquisme: la Vall d'Albaida (1938-1947). València: PUV.

Del Águila, J. J. (2001). El TOP. La represión de la libertad (1963-1977). Barcelona: Planeta.

Di Febo, G. (2006). «La cuna, la cruz y la bandera». Primer franquismo y modelos de género. En I. Morant (Dir.), Historia de las mujeres en España y América Latina. Del siglo XX a los umbrales del XXI (pp. 217-237). Madrid: Cátedra.

Díez, E. (2011). Educando la memoria de las jóvenes generaciones: el olvido escolar de la II República y de la barbarie franquista. En C. Lomas (Coord.), Lecciones contra el olvido (Memoria de la educación y educación de la memoria) (pp. 225-258). Barcelona: Octaedro. 
Díez, E. (Dir.). (2012). La Memoria Histórica en los libros de texto. León: Foro por la Memoria y Ministerio de la Presidencia.

Egido, A. (2011). Mujeres y rojas: la condición femenina como fundamento del sistema represor. Studia Histórica. Historia Contemporánea, 29, 19-34.

Fernández Ros, J.M., González, J., León, V. y Ramírez, G. (2016). Historia de España. $2^{\circ}$ Bachillerato. Madrid: Santillana.

Fuertes, C. (2017). Viviendo en dictadura. La evolución de las actitudes sociales hacia el franquismo. Granada: Comares.

Fuertes, C. (2018). La dictadura franquista en los manuales escolares recientes: una revisión crítica. Revista Historia Autónoma, 12, 171-189. DOI:10.15366/rha2018.12.015.

Fuertes, C. y Gómez, A. (2011). El Tribunal de Orden Público en el País Valenciano. Testimonios de la represión política y el antifranquismo. València: FEIS.

Fuertes, C. y Verdugo, V. (Coords.) (2017). Mujeres y represión franquista. Una guía para su estudio en Valencia. València: PUV.

García de Cortázar, F., Donézar, J.M., Valdeón, J., Del Val, M.I., Fernández, M, y GAMAZO, Á. (2016). Historia de España. $2^{\circ}$ Bachillerato. Madrid: Anaya.

García, E., Gomis, P., Latorre, F., González, J., Ramírez, G., Sebastián, R. (2003). Historia. Segundo de Bachillerato. València: Ecir.

Gil, P. (2012). Violencia en la guerra civil y equidistancia: argumentos para no sucumbir al embrujo irresistible del punto medio. Hispania Nova, 10.

Gómez, G. (2009). El exilio interior. Cárcel y represión en la España franquista, 1939-1950. Madrid: Taurus.

Gómez, G. y Marco, J. (2011). La obra del miedo. Violencia y sociedad en la España franquista (1936-1950). Barcelona: Península.

Hernández, F. (2014). La enseñanza de la historia del presente en la España actual: entre al agujero negro y el relato intencional. Studia Histórica. Historia Contemporánea, 32, 57-74.

Ibáñez, M. (2016). ¿Alguien hablará de nosotras cuando hayamos muerto? Sobre género, franquismo y didáctica. Didácticas Específicas, 14, 50-70.

Ibáñez, M. (2017). Dictadura franquista y represión femenina: la aplicación de la Ley de Responsabilidades Políticas sobre las mujeres en Valencia (1939-c.1948) (Tesis doctoral). Universitat de València, València.

Joly, M. (2008). Las violencias sexuadas de la guerra civil española: paradigma para una lectura cultural del conflicto. Historia Social, 61, 89-107.

Lamikiz, A. (2011). El lugar de la memoria en nuestras clases de historia. En R. López Facal et al. (Eds.), Pensar históricamente en tiempos de globalización: actas de I Congreso Internacional sobre enseñanza de la historia (pp. 99-110). Santiago de Compostela: USC.

Langarita, E. (2016). Viudas eternas, vestales de la patria. El "luto nacional” femenino como agente cohesionador de la España franquista. Ayer, 103, 125-145.

López Facal, R. y Santidrián, V. (2011). Los ‘conflictos sociales candentes’ en el aula. Íber. Didáctica de las Ciencias Sociales, Geografía e Historia, 69, 8-20.

Marco, J. (2012). «Debemos condenar y condenamos» ... justicia militar y represión en España (1936-1948). En J. Aróstegui (Coord.), Franco, la represión como sistema (pp. 190-229). Barcelona: Flor del Viento.

Marina, M. (2015). De democracias, dictaduras, guerras, repúblicas y monarquías: la historia reciente española en los libros de texto. En J.C. Colomer, J. Esteve y M. Ibáñez (Coords.), Ayer y hoy. Debates, historiografía y didáctica de la historia (pp. 52-55). València: PUV.

Martín, O., González, D. y Ortiz, M. (2009). “Envenenando a nuestra juventud”. Cambio de actitudes y militancia juvenil durante el segundo franquismo. Historia Actual Online, 20, 1933.

Mir, C. (1999). Violencia política, coacción legal y oposición interior. Ayer, 33, 115-146. 
Molinero, C. (1999). Mujer, franquismo, fascismo. La clausura forzada en un «mundo pequeño». Historia Social, 30, 97-117.

Molpeceres, A. (2011). Conflictos: la memoria de los alumnos. De la Guerra Civil a la transición. Íber. Didáctica de las Ciencias Sociales, Geografía e Historia, 69, 21-28.

Moreno, F. (1999). La represión en la posguerra. En S. Juliá (Coord.), Víctimas de la Guerra Civil (pp. 277-406). Madrid: Temas de Hoy.

Moreno, M. (2013). La dictadura franquista y la represión de las mujeres. En M. Nash (Ed.). Represión, resistencias y memoria. Las mujeres bajo la dictadura franquista (pp. 1-21). Granada: Comares.

Pereira, J.C. y De la Mata, A. (2016). Historia de España. $2^{\circ}$ Bachillerato. Madrid: SM.

Prades, S. (2016). Las fuentes orales en la Educación Secundaria: motivación y aprendizaje de la Historia. Didáctica de las ciencias experimentales y sociales, 30, 85-101. DOI:10.7203/DCES.30.4478

Prats, J. (2012). Criterios para la elección del libro de texto de historia. Iber. Didáctica de las Ciencias Sociales, Geografía e Historia, 70, 7-13.

Preston, P. (2011). El holocausto español. Odio y exterminio en la Guerra Civil y después. Barcelona: Debate.

Richards, M. (1999). Un tiempo de silencio. La guerra civil y la cultura de la represión en la España de Franco, 1939-1945. Barcelona: Crítica.

Rodrigo, J. (2001). Vae victis! La función social de los campos de concentración franquistas. Ayer, 43, 163-188.

Rodrigo, J. (2004). Los mitos de la derecha historiográfica. Sobre la memoria de la Guerra Civil y el revisionismo a la española. Historia del Presente, 3, 185-195.

Rodrigo, J. (2008). Hasta la raíz. Violencia durante la Guerra Civil y la dictadura franquista. Madrid: Alianza.

Rüsen, J. (1997). El libro de texto ideal. Reflexiones en torno a los medios para guiar las clases de historia. Íber. Didáctica de las Ciencias Sociales, Geografía e Historia, 12, 79-94.

Sánchez, M.L. (2012). La selectividad, un motivo de lucha contra el franquismo. Reivindicaciones estudiantiles en Zaragoza, 1970-1975. En G. Vicente (Coord.), Estudios sobre historia de la enseñanza secundaria en Aragón (pp. 381-388). Zaragoza: Institución Fernando el Católico.

Sánchez, P. (2009). Individuas de dudosa moral. Barcelona: Crítica.

Sánchez-Lafuente, J. (2008). ¿Qué tratamiento se da a la II República, a la Guerra Civil y al Franquismo en los libros de texto de historia de $4^{\circ}$ de ESO? En G. Acosta, A. Del Río y J.M. Valcuende (Coords.), La recuperación de la memoria histórica: una perspectiva transversal desde las ciencias sociales (pp. 195-202). Sevilla: Fundación Centro de Estudios Andaluces.

Santamaría, S. (2013). La palabra como acontecimiento: Segunda República, Guerra Civil y posguerra en la novela actual (1990-2010) (Tesis doctoral). Universitat de València, València.

Saz, I. (1999). Introducción. Entre la hostilidad y el consentimiento. Valencia en la posguerra. En I. Saz y A. Gómez (Eds.). El franquismo en Valencia. Formas de vida y actitudes sociales en la postguerra (pp. 9-36). València: Epísteme.

Saz, I. (2007). El «moment memòria». Justícia, veritat i reconciliació democràtica. Afers, 56, 27-40.

Saz, I. (2008). Fascismo, fascistización y desarrollismo en la dictadura franquista. En M. Burguera y C. Schmidt-Novara (Eds.), Historias de España contemporánea. Cambio social y giro cultural (171-192). València: PUV.

Valls, R. (1984). La interpretación de la Historia de España, y sus orígenes ideológicos, en el bachillerato franquista (1938-1953). València: Instituto de Ciencias de la Educación-UV.

Valls, R. (2007). La guerra civil española y la dictadura franquista: las dificultades del tratamiento escolar de un tema potencialmente conflictivo. Enseñanza de las Ciencias Sociales, 6, 61-74. 
Valls, R. (2009). Historia y memoria escolar: Segunda República, Guerra Civil y dictadura franquista en las aulas (1938-2008). València: PUV.

Vinyes, R. (2002). Irredentas: Las presas políticas y sus hijos en las cárceles de Franco, Madrid: Temas de Hoy.

Vinyes, R. (2004). Sobre la destrucción y la memoria de las presas en las afueras de la prisión. Historia del Presente, 4, 13-30.

\section{CÓMO CITAR ESTE ARTÍCULO}

Fuertes Muñoz, C. e Ibáñez Domingo, M. (2019). La represión franquista en los manuales escolares: el problemático tratamiento de un tema histórico conflictivo. Didáctica de las ciencias experimentales y sociales, 37, 3-18. DOI: 10.7203/DCES.37.12528 
